\title{
Pilot Study on Advanced Treatment of Wastewater Produced by Pressurized Coarse Coal Gasification
}

\author{
Jingzhi Zhang ${ }^{1,2, a}$, Linlin Xing ${ }^{2,3, b^{*}}$, Jiane Zuo ${ }^{1, c}$, Anping Jiang ${ }^{2, d}$, Kai Wang ${ }^{2, e}$, \\ Jinquan Liu ${ }^{2, f}$ and Yongzhen Peng ${ }^{3, g}$ \\ ${ }^{1}$ School of Environment, Tsinghua University, Beijing 100084, China \\ ${ }^{2}$ Sound Group Ltd., Beijing 101102, China \\ ${ }^{3}$ College of Environmental and Energy Engineering, Beijing University of Technology, Beijing \\ 100124, China

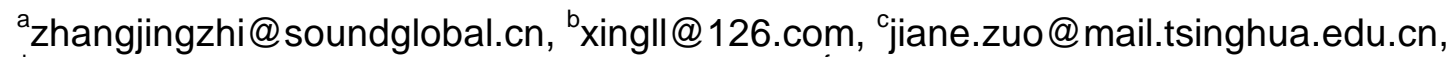

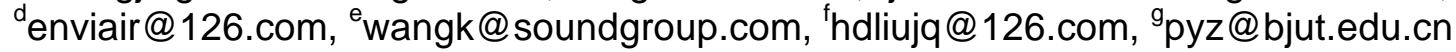 \\ *corresponding author
}

\begin{abstract}
Keywords: wastewater treatment, pressurized coarse coal gasification, advanced treatment, ozonation, pilot scale

Abstract. A Pilot study on advanced treatment of wastewater produced by pressurized coarse coal gasification was done in a coal chemical plant. The feasibility of catalytic ozonation, $\mathrm{UV} / \mathrm{O}_{3}$, and Fenton process in the advanced treatment of wastewater produced by pressurized coarse coal gasification process was studied and catalytic ozonation was proved to be a good choice with high COD removal (55\%). Furthermore, a two-stage advanced treatment process combined with advanced oxidation processes (AOPs) and biological aerated filter (BAF) was proposed to meet the requirement of ultrafiltration-reverse osmosis (UF-RO) wastewater reuse system. It was found that catalytic ozonation showed the advantage in the first stage oxidation while $\mathrm{UV} / \mathrm{O}_{3}$ process showed the advantage in the second stage oxidation. Ultimately, we developed the interesting catalytic ozonation-BAF-UV/O ${ }_{3}$-BAF process and the effluent met the UF-RO requirement of COD $<50 \mathrm{mg} / \mathrm{L}$, which opened a new and efficient channel for pressurized coarse coal gasification wastewater treatment.
\end{abstract}

\section{Introduction}

Pressurized coarse coal gasification (PCCG) process has been applied in the coal chemical industry for decades. However, the pollutant emission and the environmental problems resulted confine its application and development. The wastewater produced by this process contains high concentration of refractory organic compounds (such as phenolic compounds, aromatic hydrocarbons, heterocyclic compounds), ammonium and salt ${ }^{[1]}$ which lead to low biodegradability. The quality of wastewater treated by the widely used "pretreatment + biological treatment" process is unable to satisfy the increasingly stringent discharge standards. As a result, the advanced treatment of PCCG wastewater is necessary. The "zero discharge" policy sets an even higher requirement for wastewater treatment of coal chemical industry. The ultrafiltration (UF) and reverse osmosis (RO) are used as the reuse treatment processes. To control the membrane fouling and prolong the membrane life, the influent of UF-RO system should maintain a fairly low organic level which is much lower than the discharge standard. This challenges the advanced treatment technology, therefore, it is greatly urgent to research and develop efficient and practical advanced treatment technology.

The advanced treatment technologies of PCCG wastewater include biological and physical-chemical treatment technologies. The biological advanced treatment technologies include mainly biological aerated filter and membrane bioreactor ${ }^{[2-4]}$. The physical-chemical advanced treatment technologies include coagulation, adsorption, membrane separation, advanced oxidation process (AOP), et al. The biological treated PCCG wastewater still contains a large number of toxic and refractory compounds as well as their derivatives. Therefore, AOP is widely studied as advanced 
treatment process as it generate hydroxyl radical ( $\mathrm{HO} \bullet)$, which is a powerful oxidizer and can oxidize almost all the organic contaminants in water. The AOPs studied include ozonation related AOPs, Fenton's reaction, electro-chemical related AOPs, photocatalysis, ultrasonic treatment ${ }^{[3,5-8]}$, et al. Most of the AOPs are under experimental study and lack practicality. Commercially available processes include Fenton process and ozonation related processes. As the biological treated PCCG wastewater contains not only compounds which can be oxidized by ozone molecule rapidly, such as phenol $\left(k_{\mathrm{O} 3}=18 \times 10^{6} \mathrm{M}^{-1} \mathrm{~s}^{-1}\right.$ at $\left.\mathrm{pH} 8^{[9]}\right)$; but also those cannot be oxidized by ozone molecule but can be oxidized by $\mathrm{HO} \bullet$ rapidly, such as pyridine $\left(k_{\mathrm{O} 3}=3 \mathrm{M}^{-1} \mathrm{~s}^{-1}[10], k_{\mathrm{HO}} \cdot=3 \times 10^{9[11]}\right)$. This makes ozonation related AOPs such as catalytic ozonation and $\mathrm{UV} / \mathrm{O}_{3}$ process potential advanced treatment processes for PCCG wastewater. In this paper, catalytic ozonation, $\mathrm{UV} / \mathrm{O}_{3}$, and Fenton process were selected to study their feasibility in the advanced treatment of PCCG wastewater. An advanced treatment process combined with AOPs and biological aerated filter (BAF) were proposed and studied to meet the requirement of UF-RO wastewater reuse system.

\section{Materials and methods}

The pilot-scale experimental facility was set up in a coal chemical industry enterprise, which produced methanol and liquefied natural gas with the PCCG process. The pilot facility was used to treat PCCG wastewater. The anaerobic and aerobic biological treatment was used as the main treatment process, the demulsification was used as pretreatment process, and the AOPs were used as advanced treatment process. In this paper, the comparison and selection of advanced treatment process was studied. The effluent of aerobic biological treatment was coagulated and was used as the influent of advanced treatment process, and this coagulated PCCG wastewater was called C-PCCG wastewater for short in the following part. The water quality parameters of the C-PCCG wastewater were as follows: COD, $258 \sim 320 \mathrm{mg} / \mathrm{L} ; \mathrm{NH}_{4}{ }^{+}-\mathrm{N}, 0.2 \sim 7 \mathrm{mg} / \mathrm{L} ; \mathrm{pH}, 7.4 \sim 8.1$; temperature, $30^{\circ} \mathrm{C}$. The sizes of catalytic ozonation $\left(\mathrm{CatO}_{3}\right)$ reactor and $\mathrm{UV} / \mathrm{O}_{3}$ reactor were both $1 \times 1 \times 2.5 \mathrm{~m}$. Both of the effective volumes were about $2 \mathrm{~m}^{3}$. The sizes of the first BAF (BAF1) and the second BAF (BAF2) were both $\Phi 1.25 \times 3$ $\mathrm{m}$. And their effective volumes were about $3 \mathrm{~m}^{3}$. The sizes of the first sand filter (SF1) and second sand filter (SF2) were both $\Phi 0.35 \times 1.65 \mathrm{~m}$. The Fenton reactor had an effective volume of $2 \mathrm{~m}^{3}$. The process flow chart of the two-stage AOP-BAF was shown in Figure 1.

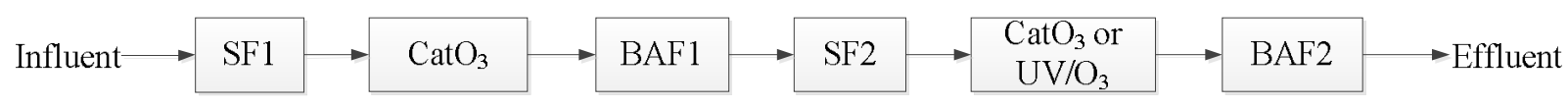

Fig. 1 Process flow chart of the two-stage AOP-BAF

The pilot experiments were conducted in a continuous system. Ozone was generated from pure oxygen using an ozone generator (CF-G-2-600g, GUOLIN). The flow rate of wastewater was about 1 $\mathrm{m}^{3} / \mathrm{h}$, and the flow rate of the gaseous mixture of ozone was about $2 \mathrm{~m}^{3} / \mathrm{h}$.

COD was analyzed with the fast digestion-spectrophotometric method (Chinese trade standard HJ/T 399-2007). Gaseous ozone concentration was determined with an ozone detector (UV-500, IDEAL)

COD removal $(\%)$, and ozone efficiency (dimensionless) were calculated using the following equations:

$$
\begin{aligned}
& \text { COD removal }=\left(1-\frac{C O D_{\mathrm{O}}}{C O D_{\mathrm{I}}}\right) \times 100 \% \\
& \text { Ozone efficiency }=\frac{\left(C O D_{\mathrm{I}}-C O D_{\mathrm{O}}\right) Q_{\mathrm{W}}}{\left(C_{\mathrm{O}_{3} \mathrm{I}}-C_{\mathrm{O}_{3} \mathrm{O}}\right) Q_{\mathrm{G}}}
\end{aligned}
$$


where $\mathrm{COD}_{\mathrm{I}}$ and $\mathrm{COD}_{\mathrm{O}}$ are the $\mathrm{COD}(\mathrm{mg} / \mathrm{L})$ in the influent and effluent of water treatment unit, respectively; $C_{\mathrm{O}_{3} \mathrm{I}}$ and $C_{\mathrm{O}_{3} \mathrm{O}}$ are the inlet and outlet concentrations $(\mathrm{mg} / \mathrm{L})$ of gaseous ozone, respectively; $\mathrm{Q}_{\mathrm{W}}$ and $\mathrm{Q}_{\mathrm{w}}$ are the flow rate $\left(\mathrm{m}^{3} / \mathrm{h}\right)$ of the wastewater and ozone gas mixture.

\section{Results and discussion}

Catalytic ozonation process. The effect of power of ozone generator on the catalytic ozonation is presented in Figure 2. The concentration of gaseous ozone depends on the power of ozone generator. The ozone concentrations are 60,70 , and $90 \mathrm{mg} / \mathrm{L}$ when the powers of ozone generator are $1.5,2$ and $3 \mathrm{~kW}$, respectively. The COD removal is $36 \%$ when no catalyst is added and the power of ozone generator is $2 \mathrm{~kW}$ (the first column in Figure 3). The COD removal is 55\% when the same power of ozone generator is applied to the catalytic ozonation system (Figure 2), which indicates that catalyst greatly enhances the COD removal during the ozonation process. In this case, the catalyst can accelerate the generation of hydroxyl radical (HO-) ${ }^{[12]}$ which reacts with almost all the organic contaminants in water. The refractory organics in C-PCCG wastewater, which cannot be oxidized by ozone molecule, are oxidized by HO. Fig. 2(a) shows that the COD removal increases and then decreases as the power of ozone generator increases from 1.5 to $3 \mathrm{~kW}$. It indicates that bigger ozone dosage can increase the COD removal; however, excess ozone dosage weakens the COD removal. It is because high concentration of ozone in wastewater enhances the radical type chain reaction of ozone self-decomposition, which lowers the ozone efficiency to decompose the organic pollutants in wastewater. As shown in Fig. 2(b), ozone efficiency decreases as the ozone dosage increases, and the ozone efficiency is much lower when the power of ozone generator is $3 \mathrm{~kW}$ compare to the other two. It also indicates that when ozone dosage is lower, the probability of ozone self-decomposition is lower and the probability of ozone reaction with organic contaminant is higher, and vice versa. According to the results of Fig. 2, for catalytic ozonation, the ozone generator power of $2 \mathrm{~kW}$, namely the gaseous ozone concentration of $70 \mathrm{mg} / \mathrm{L}$ is the optimal operation conditions.

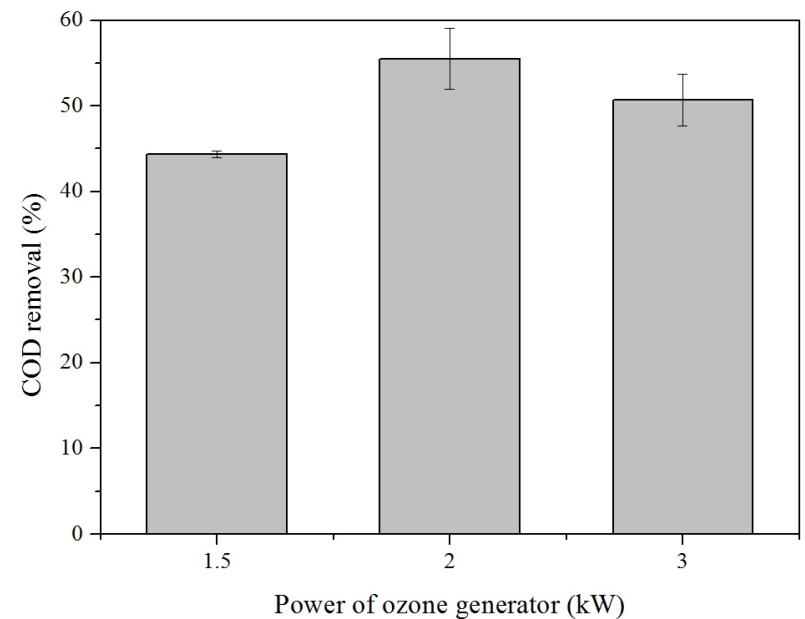

(a)

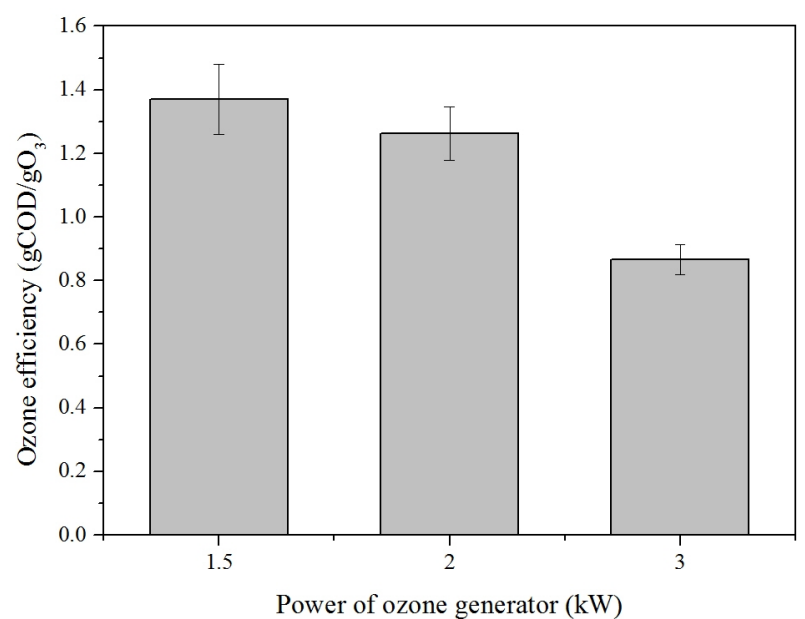

(b)

Fig. 2 Effect of power of ozone generator on COD removal (a) and ozone efficiency (b)

$\mathrm{UV} / \mathrm{O}_{3}$ process. The effect of power of UV light on the $\mathrm{UV} / \mathrm{O}_{3}$ process is evaluated and the results are shown in Figure 3. The power of ozone generator is $2 \mathrm{~kW}$ in this experiment. Fig. 3 shows that the application of UV light in ozonation system cannot increase the COD removal and ozone efficiency under the experimental conditions. However, the COD removal and ozone efficiency did increase with the power of $\mathrm{UV}$ light. It is reported that the first step of $\mathrm{UV} / \mathrm{O}_{3}$ process is the formation of $\mathrm{H}_{2} \mathrm{O}_{2}$ by photolysis of $\mathrm{O}_{3}$ through reaction (3) ${ }^{[13]}$. Then the dissociation product of $\mathrm{H}_{2} \mathrm{O}_{2}, \mathrm{HO}_{2}$, initiates the radical type chain reaction of ozone decomposition to generate $\mathrm{HO}{ }^{[14]}$. The photolysis of $\mathrm{H}_{2} \mathrm{O}_{2}$ also generates $\mathrm{HO} \cdot{ }^{[13]}$. The brown color of C-PCCG wastewater weakens the penetration of UV 
light, which leads to the generation of $\mathrm{H}_{2} \mathrm{O}_{2}$ near the UV lambs. Thus, the photolysis of $\mathrm{H}_{2} \mathrm{O}_{2}$ generates $\mathrm{HO}$. near the UV lambs; $\mathrm{HO}_{2}{ }^{-}$also prefers to initiates the radical chain reaction of ozone decomposition to generate $\mathrm{HO} \cdot$ near the UV lambs. However, high concentration of $\mathrm{HO}$. tends to terminate through reaction (4). The higher concentration of $\mathrm{H}_{2} \mathrm{O}_{2}$ near the UV lambs also reacts with $\mathrm{HO}$, which decreases the reaction between $\mathrm{HO}$. and refractory organics in water. This explains the lower COD removal and ozone efficiency when UV light is applied. As the power of UV light is increased, the penetration of UV light is enhanced, and more HO-s are generated in bulk solution to oxidize the organic contaminants in wastewater. UV light do not enhance the COD removal even the power of UV light is increased to $4.8 \mathrm{~kW}$, so continue to increase the power of UV light to increase the COD removal is uneconomical.

$$
\begin{aligned}
& \mathrm{O}_{3}+\mathrm{H}_{2} \mathrm{O}+\mathrm{UV} \text { light } \rightarrow \mathrm{O}_{2}+\mathrm{H}_{2} \mathrm{O}_{2} \\
& \mathrm{HO} \square+\mathrm{HO} \rightrightarrows \mathrm{H}_{2} \mathrm{O}_{2}
\end{aligned}
$$

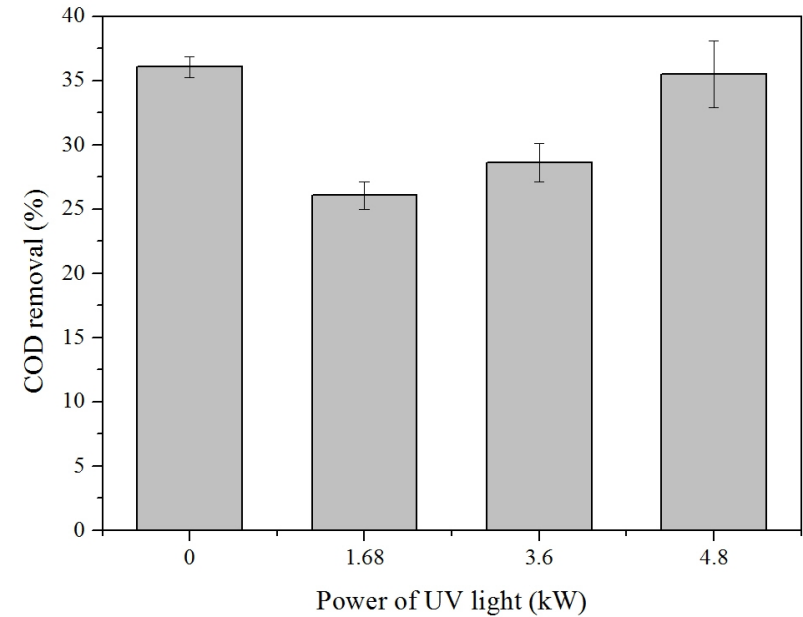

(a)

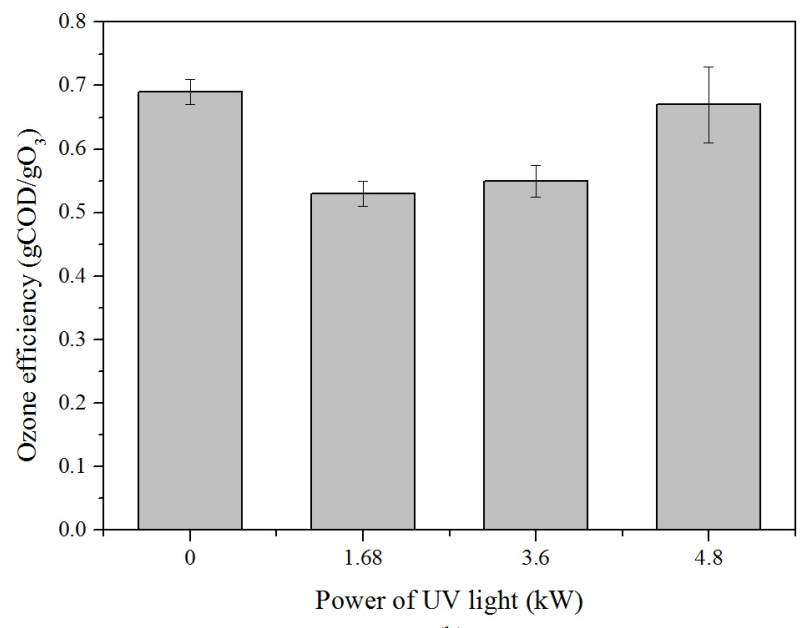

(b)

Fig. 3 Effect of UV light power on COD removal (a) and ozone efficiency (b)

Fenton process. The effect of the dosage of Fenton's reagent on the C-PCCG wastewater treatment is studied and the corresponding results are shown in Figure 4. The reaction $\mathrm{pH}$ is adjusted to 3.5 by adding sulphuric acid, and the molar ratio of $\mathrm{Fe}^{2+}$ and $\mathrm{H}_{2} \mathrm{O}_{2}$ is $1: 10$. The $\mathrm{pH}$ of wastewater is adjusted to 8 and $2 \mathrm{mg} / \mathrm{L}$ polyacrylamide is added to flocculate the precipitate produced after the Fenton reaction. Fig. 4 shows that when $5 \mathrm{mM} \mathrm{H}_{2} \mathrm{O}_{2}$ is added, the COD removal is about 50\%, and increasing the dosage of $\mathrm{H}_{2} \mathrm{O}_{2}$ improves the COD removal slightly. As Fenton's reaction is characterized by the generation of $\mathrm{HO}$, it is suitable for this refractory C-PCCG wastewater. However, Fenton's reaction have several disadvantages: (a) it produces considerable chemical sludge (about 5\% for $5 \mathrm{mM} \mathrm{H}_{2} \mathrm{O}_{2}$ addition in this experiment); (b) many reagents (five reagents in this experiment) are added to ensure the success of the reaction; (c) It is not easy to adjust the $\mathrm{pH}$ during and after the reaction as the $\mathrm{pH}$ of the wastewater fluctuates; (d) the $\mathrm{pH}$ adjusted after the Fenton's reaction affects the precipitation produced and make the flocculation hard to control. 


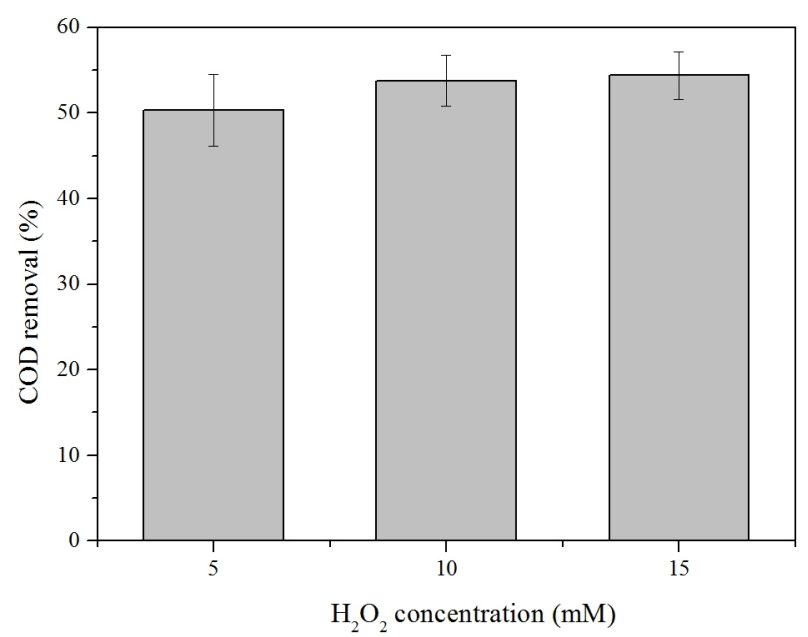

Fig. 4 Effect of Fenton's reagent dosage on COD removal

Two-stage AOP-BAF advanced treatment. As previous statement, $\mathrm{UV} / \mathrm{O}_{3}$ process is inefficient and Fenton process has many drawbacks. Catalytic ozonation process is efficient, economic and reliable in operation. Thus, catalytic ozonation is selected as the advanced treatment process for C-PCCG wastewater treatment. However, although the COD removal achieves 55\% under the optimal operation conditions in catalytic ozonation process, the COD of the effluent is still higher than 100 $\mathrm{mg} / \mathrm{L}$, which is beyond the requirement of $50 \mathrm{mg} / \mathrm{L}$ for UF-RO reuse treatment. The C-PCCG wastewater reveals low biodegradability with only 0.07 of $\mathrm{BOD}_{5} / \mathrm{COD}$ value. The $\mathrm{BOD}_{5} / \mathrm{COD}$ value increases to 0.29 (data not shown) after the catalytic ozonation treatment with the power of ozone generator $2 \mathrm{~kW}$, which indicates the combination of catalytic ozonation with biological treatment is feasible. BAF is selected as the biological advanced treatment unit. In order to obtain higher biodegradable water for BAF after ozonation and achieve the fairly low COD level for UF-RO reuse treatment, we propose a two-stage AOP-BAF advanced treatment process. Catalytic ozonation is selected as the first-stage AOP for its good performance. Both catalytic ozonation and $\mathrm{UV} / \mathrm{O}_{3}$ are studied as the second-stage AOP. The treatment results are shown in Table 1. The power of ozone generator and UV light is $2 \mathrm{~kW}$ and $1.68 \mathrm{~kW}$, respectively. The experiment with $\mathrm{O}_{3}-\mathrm{BAF}-\mathrm{O}_{3}-\mathrm{BAF}$ process is done for control. It is shown that for the first stage the COD removed by catalytic ozonation is about $45 \%$ higher than the individual ozonation process. The BAF in the first stage removes about $20 \%$ of COD for all the experiment. The sand filtration of the second stage slightly decreases the COD of the wastewater. Compare to the individual ozonation process in the second stage, the catalytic ozonation does not show significant improvement in COD removal, but $\mathrm{UV} / \mathrm{O}_{3}$ process removes more $\mathrm{COD}$ than the other two. The higher COD removal of $\mathrm{UV} / \mathrm{O}_{3}$ system may because after the treatment of the first stage, the wastewater is decolorized and the penetration of the UV light is significantly enhanced, which lead to more HO-s generated in bulk solution. Therefore, the catalytic ozonation is suitable for the first-stage oxidation, and the $\mathrm{UV} / \mathrm{O}_{3}$ is suitable for the second-stage oxidation. The $\mathrm{BAF}$ in the second stage removed about $11 \%$ of COD for all the experiment. Although the COD of SF1 effluent is about $40 \mathrm{mg} / \mathrm{L}$ higher for $\mathrm{CatO}_{3}-\mathrm{BAF}-\mathrm{UV} / \mathrm{O}_{3}-\mathrm{BAF}$ process than that for $\mathrm{CatO}_{3}-\mathrm{BAF}-\mathrm{CatO}_{3}$-BAF process, the effluent $\mathrm{COD}$ of the former is equivalent to that of the latter. The effluent COD is lower than the requirement of $50 \mathrm{mg} / \mathrm{L}$ for the UF-RO system. According to the above discussion, we come to a conclusion that $\mathrm{CatO}_{3}-\mathrm{BAF}-\mathrm{UV} / \mathrm{O}_{3}-\mathrm{BAF}$ process is a suitable process for C-PCCG wastewater advanced treatment.

Table 1 COD results of various two-stage AOP-biological treatments

\begin{tabular}{|c|c|c|c|c|c|c|}
\hline $\begin{array}{c}\text { Anvanced treatment } \\
\text { process }\end{array}$ & $\begin{array}{c}\text { COD of SF1 } \\
\text { effluent } \\
\text { [mg/L] }\end{array}$ & $\begin{array}{c}\text { COD of O1 } \\
\text { effluent } \\
{[\mathrm{mg} / \mathrm{L}]}\end{array}$ & $\begin{array}{c}\mathrm{COD} \text { of BAF1 } \\
\text { effluent } \\
{[\mathrm{mg} / \mathrm{L}]}\end{array}$ & $\begin{array}{c}\text { COD of SF2 } \\
\text { effluent } \\
{[\mathrm{mg} / \mathrm{L}]}\end{array}$ & $\begin{array}{c}\text { COD of O2 } \\
\text { effluent } \\
{[\mathrm{mg} / \mathrm{L}]}\end{array}$ & $\begin{array}{c}\text { COD of BAF2 } \\
\text { effluent } \\
\text { [mg/L] }\end{array}$ \\
\hline $\mathrm{O}_{3}$-BAF-O 3 -BAF & $273 \pm 10$ & $172 \pm 9$ & $139 \pm 8$ & $122 \pm 10$ & $94 \pm 6$ & $82 \pm 7$ \\
\hline $\mathrm{CatO}_{3}-\mathrm{BAF}-\mathrm{CatO}{ }_{3}-\mathrm{BAF}$ & $270 \pm 8$ & $124 \pm 8$ & $98 \pm 9$ & $90 \pm 10$ & $64 \pm 5$ & $47 \pm 4$ \\
\hline $\mathrm{CatO}_{3}-\mathrm{BAF}-\mathrm{UV} / \mathrm{O}_{3}-\mathrm{BAF}$ & $310 \pm 7$ & $142 \pm 12$ & $118 \pm 4$ & $106 \pm 7$ & $62 \pm 4$ & $45 \pm 5$ \\
\hline
\end{tabular}




\section{Conclusion}

The pilot study shows that catalyst significantly improves the COD removal and ozone efficiency in ozonation system, which makes catalytic ozonation a good choice for C-PCCG wastewater advanced treatment. The UV light cannot improve the COD removal and ozone efficiency in the ozonation of $\mathrm{C}-\mathrm{PCCG}$ wastewater. The Fenton process shows advantage in COD removal, but has many disadvantages in operation. Therefore, $\mathrm{UV} / \mathrm{O}_{3}$ and Fenton process is not suitable for C-PCCG wastewater treatment.

A two-stage AOP-BAF advanced treatment process is designed to meet the UF-RO requirement of $\mathrm{COD}<50 \mathrm{mg} / \mathrm{L}$. Catalytic ozonation shows the advantage in the first stage oxidation and $\mathrm{UV} / \mathrm{O}_{3}$ process shows the advantage in the second stage oxidation, thus $\mathrm{CatO}{ }_{3}-\mathrm{BAF}-\mathrm{UV} / \mathrm{O}_{3}-\mathrm{BAF}$ process is proved an efficient advanced treatment process.

\section{Acknowledgements}

Authors gratefully acknowledge finical support of Major Science and Technology Program for Water Pollution Control and Treatment (2014ZX07211-001)

\section{References}

[1] W. Wang, H. Han, M. Yuan, et al, Bioresour. Technol. 102 (2011) 5454-5460.

[2] H. Zhuang, H. Han, S. Jia, et al, Bioresour. Technol. 157 (2014) 223-230.

[3] S. Jia, H. Han, H. Zhuang, et al, Bioresour. Technol. 189 (2015) 426-429.

[4] S. Jia, H. Han, B. Hou, et al, Chemosphere. 117 (2014) 753-759.

[5] H. Zhuang, H. Han, B. Hou, et al, Bioresour. Technol. 166 (2014) 178-186.

[6] P. Xu, H. Han, H. Zhuang, et al, Bioresour. Technol. 182 (2015) 389-392.

[7] S. Jia, H. Han, B. Hou, et al, Bioresour. Technol. (2015) 12-20.

[8] P. Xu, H. Han, B. Hou, et al, Bioresour. Technol. 189 (2015) 417-420.

[9] J. Hoigné, H. Bader, Water Res. 17 (1983) 185-194.

[10] J. Hoigné, H. Bader, Water Res. 17 (1983) 173-183.

[11] S. Solar, N. Getoff, K. Sehested, et al, Radiat. Phys. Chem. 41 (1993) 825-834.

[12] J. Nawrocki, B. Kasprzyk-Hordern, Appl. Catal., B. 99 (2010) 27-42.

[13] J.C. Crittenden, R.R. Trusssell, D.W. Hand, et al, Water treatment: principles and design, third ed., John Wiley \& Sons, Hoboken, 2012.

[14] J. Staehelln, J. Hoigné, Environ. Sci. Technol. 19 (1985) 1206-1213. 